\title{
Perangkat Lunak Berbasis Opensource di Bidang Telekomunikasi Untuk Menumbuhkan Minat Siswa di Purwakarta Terhadap Teknologi
}

\author{
Galura Muhammad Suranegara', Ichwan Nul Ichsan², Endah Setyowati ${ }^{3}$ \\ 1,2,3Program Studi Sistem Telekomunikasi, Universitas Pendidikan Indonesia \\ *e-mail: galurams@upi.edu ${ }^{1}{ }^{*}$ ichwannul.ichsan90@upi.edu ${ }^{2}$, endahsetyowati@upi.edu ${ }^{3}$
}

\begin{abstract}
Nowadays, opensource-based technology has begun spreaded into telecommunications field. It can be seen by the number of distributed opensource-based software tools at telecommunications field. The use of opensource based software has a huge impact both on the speed of innovation and for any individual that involved in opensource based projects. The Sistem Telekomunikasi Study Program from Universitas Pendidikan Indonesia Purwakarta Regional Campus has held an opensource introduction activity in the field of telecommunications for high school students (SMA, MA, SMK) in Purwakarta at August 29, 2020. This activity aims to introduce the opensource paradigm to grow their interest and attraction of participants to start looking at source code, trying to use it thus they can contribute to opensource projects. Activities are held offline according to the Covid-19 protocol using blended learning method. The results of the activity showed that the participants were very satisfied with the event and interested in further learning about opensource based tools.
\end{abstract}

Keywords: opensource technologies, community service program, high school, purwakarta

\begin{abstract}
Abstrak
Saat ini teknologi berbasis opensource sudah meluas hingga bidang telekomunikasi. Hal ini dibuktikan dengan banyaknya sebaran perangkat perangkat khususnya perangkat lunak berbasis opensource di bidang telekomunikasi. Penggunaan perangkat lunak berbasis opensource ini memiliki dampak yang sangat besar baik bagi kecepatan inovasi maupun bagi individu yang terlibat proyek berbasis opensource. Program studi Sistem Telekomunikasi Universitas Pendidikan Indonesia Kampus Daerah Purwakarta telah menyelenggarakan kegiatan pengenalan opensource di bidang telekomunikasi untuk siswa sekolah tingkat menengah atas (SMA, MA, SMK) di Kabupaten Purwakarta pada 29 Agustus 2020. Kegiatan ini bertujuan untuk memperkenalkan paradigma opensource kepada peserta guna menumbuhkan minat dan daya tarik peserta supaya mulai melihat source code, mencoba menggunakan hingga dapat berkontribusi kepada proyek yang bersifat opensource. Kegiatan diselenggarakan secara luring sesuai protokol Covid-19 dengan metode blended learning. Hasil kegiatan menunjukkan bahwa peserta sangat puas dengan acara yang diselenggarakan dan tertarik untuk memperlajari lebih lanjut perangkat berbasis opensource.
\end{abstract}

Kata kunci: teknologi opensource, program pengabdian kepada masyarakat, Sekolah Menengah Atas, Purwakarta

\section{PENDAHULUAN}

Program studi (prodi) Sistem Telekomunikasi Universitas Pendidikan Indonesia (UPI) kampus Purwakarta merupakan prodi yang saat ini memasuki tahun kedua operasinya sejak tahun 2019. Prodi ini didirikan guna memenuhi kebutuhan saat ini berkaitan dengan pesatnya perkembangan dan kemajuan dibidang telekomunikasi di Indonesia maupun global.

Hadirnya paradigma baru di bidang jaringan telekomunikasi yang memiliki karakteristik opensource membawa dampak baru yang sangat positif untuk memepercepat inovasi produk yang dikembangkan maupun meningkatkan keterampilan para pengembang yang terlibat di dalamnya. Saat ini, perangkat-perangkat jaringan berbasis opensource di bidang telekomunikasi sudah banyak dikembangkan mulai dari melakukan emulasi jaringan berbasis software defined networking (SDN) hingga membangun sendiri jaringan berbasis SDN. Selain itu, proyek berbasis opensource juga melegalkan penggunanya untuk memodifikasi konfigurasi yang terdapat di dalam sebuah produk sesuai kehendak penggunanya.

Seperti prodi lain di Indonesia, prodi Sistem Telekomunikasi UPI juga memiliki visi dan misi yang dilandaskan pada pilar-pilar Tridharma Perguruan Tinggi, yakni Pengajaran, 
Penelitian \& Pengembangan, dan Pengabdian Masyarakat sesuai dengan bidang kelimuannya yakni telekomunikasi. Salah satu misinya adalah "menyelenggarakan pengabdian kepada masyarakat dalam rangka mengembangkan keilmuan dan berupaya memecahkan masalah dalam bidang telekomunikasi di masyarakat untuk menunjang kemajuan bangsa". Atas dasar tersebut, prodi Sistem Telekomunikasi UPI melaksanakan salah satu misinya yaitu pengabdian kepada masyarakat (PKM) seperti kegiatan tahun lalu melalui pengenalan opensource di bidang telekomunikasi yang ditujukan untuk sekolah-sekolah tingkat menengah di Purwakarta, Jawa Barat. Kerangka jaringan telekomunikasi yang di pilih adalah jaringan telekomunikasi berbasis SDN karena teknologi ini disinyalir akan turut memperkuat pengembangan teknologi 5G.

\section{METODE}

Kegiatan ini ditujukan untuk siswa tingkat menengah atas (SMA/MA/SMK) yang berada di Purwakarta, Jawa Barat. Karena kegiatan ini mematuhi protokol Covid-19, maka jumlah peserta dibatasi sebanyak 20 peserta yang berasal dari seluruh wilayah Purwakarta. Tempat pelaksanaan kegiatan yang dipilih adalah kampus UPI Purwakarta karena alasan geografisnya yang strategis sehingga mudah dijangkau oleh peserta. Peserta kegiatan ini berasal dari 5 sekolah yaitu SMKN 1 Purwakarta, SMKN 1 Cibatu, SMAN 1 Purwakarta, SMAN 1 Maniis, MAN Purwakarta. Berikut adalah jarak masing-masing asal sekolah peserta kegiatan terhadap venue:

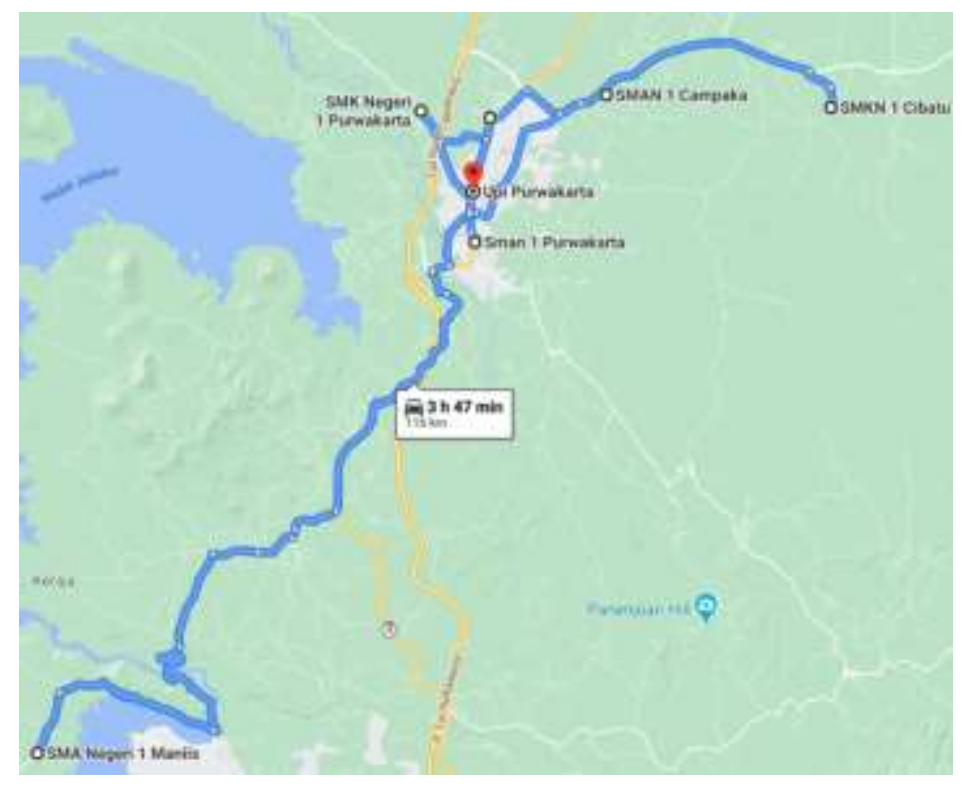

Gambar 1. Lokasi Sekolah Asal Peserta

Pelaksana program PKM ini adalah dosen-dosen program studi Sistem Telekomunikasi Universitas Pendidikan Indonesia kampus Purwakarta, Jawa Barat, yakni: Galura Muhammad Suranegara, S.Pd., M.T. (bidang keahlian Telematika), Endah Setyowati, S.T., M.T. (bidang keahlian telekomunikasi) dan Ichwan Nul Ichsan, S.T., M.T. (bidang keahlian Telekomunikasi) yang mana sangat kompeten dibidangnya.

Kegiatan ini diselenggarakan dengan metode yang hampir sama dengan pelatihan yang selenggarakan oleh Lisnawita dkk, bedanya pada kegiatan ini diberikan tugas (blended learning) yang dapat dikerjakan di rumah guna memperdalam pemahaman peserta terhadap opensource. Tahapan pertama yang dilakukan adalah peserta mendapatkan soal pre-test untuk mengetahui kemampuan awal peserta. Tahapan kedua adalah membagikan modul kegiatan yang dilanjutkan dengan pemberian materi terkait opensource di bidang telekomunikasi termasuk demonstrasi bagaimana cara mengakses repository proyek berbasis opensource. Tahapan ketiga, peserta 
dipersilahkan mengajukan pertanyaan yang dilanjutkan dengan post-test dan pemberian angket untuk evaluasi. Pada tahapan terakhir peserta diberikan tugas terkait jaringan telekomunikasi berbasis SDN guna memperdalam pemahaman mereka terhadap opensource di bidang telekomunikasi.

\section{HASIL DAN PEMBAHASAN}

Kegiatan pengabdian kepada masyarakat ini diselenggarakan secara luring di laboraturium TIK A Gedung baru lantai 2, Universitas Pendidikan Indonesia Kampus Purwakarta pada tanggal 29 Agustus 2020. Sesuai dengan protokol Covid-19, setiap peserta yang akan memasuki ruangan di arahkan untuk mencuci tangan menggunakan sabun antiseptik di tempat yang sudah disediakan. Kemudian, setiap peserta dicek suhu tubuhnya menggunakan thermo gun untuk memastikan suhu tubuhnya dibawah 37,5 derajat Celsius. Selanjutnya, peserta diarahkan agar memakai masker dan sarung tangan latex yang sudah disediakan sebelumnya.

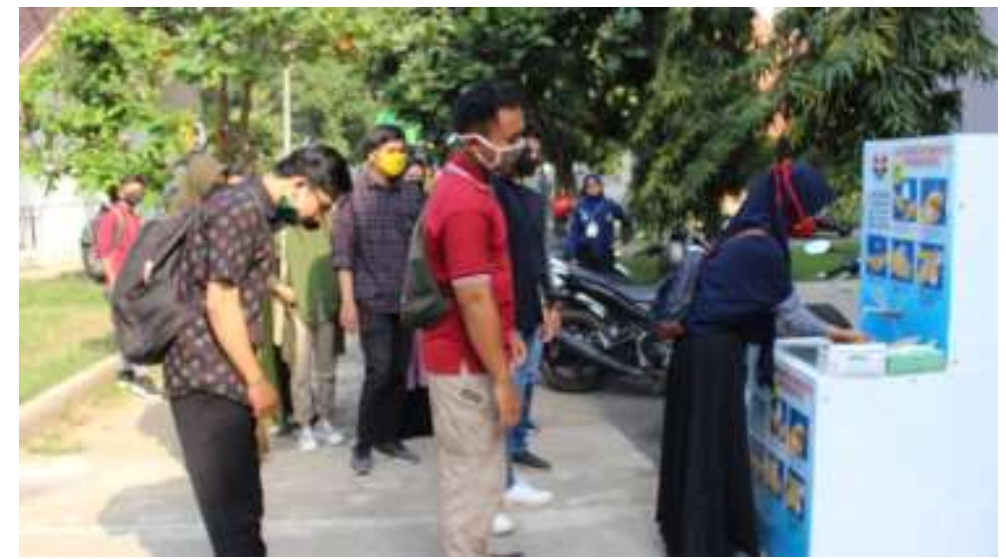

Gambar 2. Peserta Mencuci Tangan (Protokol Covid-19)

Setelah seluruh peserta menjalankan protokol Covid-19, peserta dibekali dengan seminar kit lalu dipersilahkan memasuki ruangan. Setelah memasuki ruangan, peserta di berikan brainstorming terkait topik kegiatan kemudian dilanjutkan dengan pre-test selama 15 menit kemudian dilanjutkan dengan pemberian modul kegiatan, materi dan demonstrasi selama 110 menit.

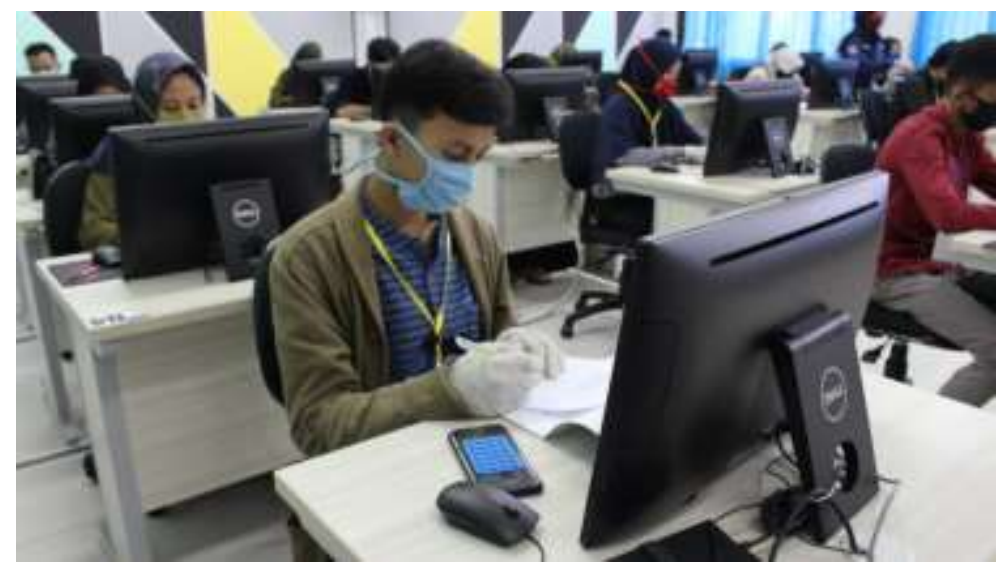

Gambar 3. Peserta Mengerjakan Soal Pre-Test 
Setelah sesi pemberian materi selesai, peserta dipersilahkan bertanya kemudian dilanjutkan dengan pemberian post-test, kuesioner terkait kegiatan dan tugas untuk dikerjakan di rumah masing-masing.

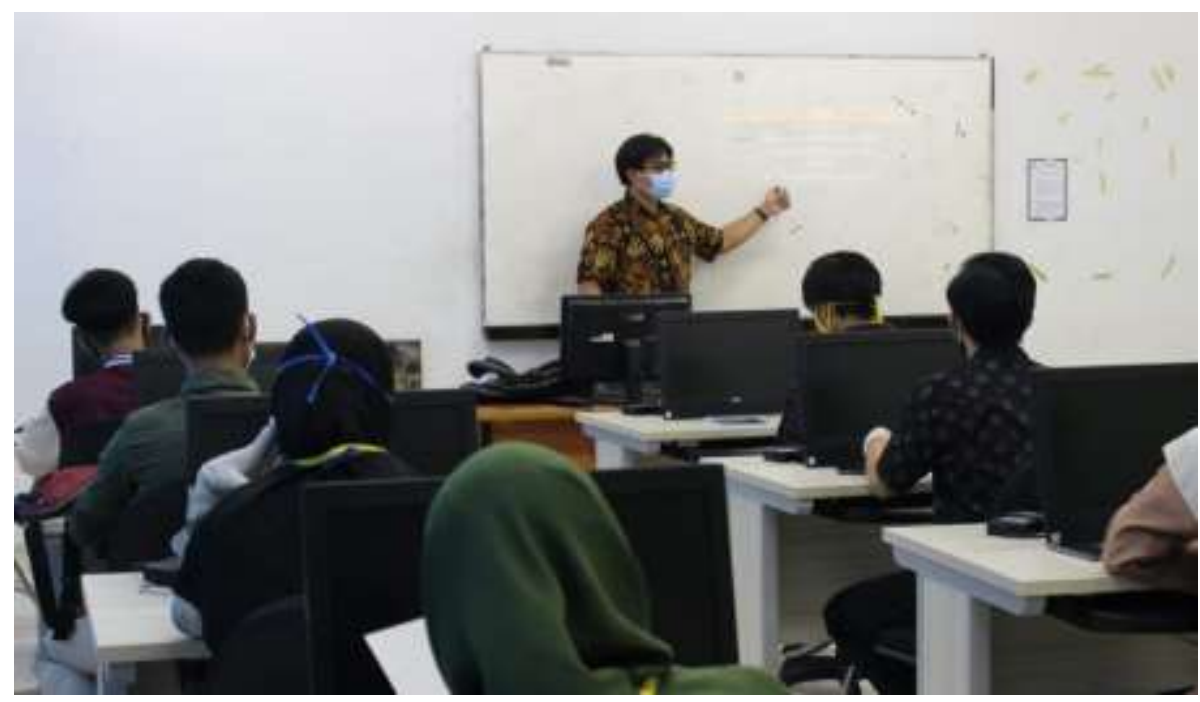

Gambar 4. Pemateri Memperkenalkan Opensource

Dengan adanya form kuesioner ini, pelaksana PKM mendapati dua jenis data yakni kuantitatif dan kualitatif. Kuesioner yang diberikan terdiri dari 17 (tujuh belas) butir pertanyaan dalam kuisioner dimana jawaban hanya berisi angka yakni skala 1 (satu) sampai skala 4 (empat) dengan keterangan sebagai berikut: skala $1=$ sangat tidak setuju, skala $2=$ tidak setuju, skala $3=$ setuju, skala 4 = sangat setuju. Kuisioner tertutup mencakup 3 (tiga) aspek utama, yakni acara, isi materi, dan penyampaian materi. Jumlah peserta adalah 20 orang, sehingga nilai maksimum apabila keseluruhan peserta menjawab skor 4 adalah 80 atau persentase maksimum 100\%. Sedangkan total nilai yang didapat, bergantung dari isian peserta. Apabila semua peserta memberikan nilai 1 , jumlah terendahnya adalah 20 atau persentase minimum $25 \%$. Selisih antara persentase maksimum terhadap persentase minimum adalah 75\%. Tim PKM menggunakan empat tingkatan skala likert (1 s.d. 4) dengan demikian kelas interval juga dibagi menjadi empat tingkatan.

Peserta dianggap puas apabila respon yang diberikan berada pada rentang $(62,51 \%$ $81,25 \%)$ dan sangat puas apabila respon yang diberikan berada pada rentang $(81,26 \%-100 \%)$. Berdasarkan kriteria tersebut, maka didapatkan hasil sebagai berikut: 1) peserta sangat puas terhadap berlangsungnya acara secara keseluruhan, dalam hal ini ditunjukkan dengan persentase $87 \%$; 2) isi materi yang di sampaikan oleh instruktur dianggap sangat memuaskan dengan persentase 86\%; dan 3) menurut peserta, cara penyampaian materi sudah sangat memuaskan dengan persentase 85\%. Data yang didapat, secara lengkap direpresentasikan pada Tabel 1.

Tabel 1. Respon Kuesioner Peserta

\begin{tabular}{lc}
\hline Aspek Utama & Persentase \\
\hline Acara & $87 \%$ \\
Isi Materi & $86 \%$ \\
Penyampaian Materi & $85 \%$ \\
\hline
\end{tabular}




\section{KESIMPULAN}

Kegiatan pengenalan opensource di bidang telekomunikasi untuk siswa sekolah tingkat menengah di Kabupaten Purwakarta, Jawa Barat telah diselenggarakan dengan baik, mulai dari persiapan, pelaksanaan hingga proses evaluasi. Seluruh aktivitas kegiatan diselenggarakan secara luring mengikuti protokol Covid-19. Peserta yang mengikuti kegiatan berjumlah 20 orang yang berasal dari lima sekolah yang terdiri dari SMA, MA dan SMK. Berdasarkan hasil evaluasi yang didapat dari kuesioner respon peserta menunjukkan bahwa mereka sangat puas dengan pelaksanaan kegiatan ini (diatas 81,26\%). Salah satu peserta memberikan saran agar kegiatan serupa digelar lebih sering agar lebih banyak lagi yang memahami tentang opensource.

\section{UCAPAN TERIMA KASIH}

Kegiatan pengabdian kepada masyarakat ini disponsori oleh Program Studi Sistem Telekomunikasi UPI Kampus Purwakarta dan LPPM Universitas Pendidikan Indonesia (UPI) tahun anggaran 2020 dengan SK Direktur nomor 627/UN40.C4/PM/2020 serta dukungan tim pengabdian kepada masyarakat dalam hal penyediaan kit-kit untuk sarana dan prasarana selama kegiatan. Kegiatan PKM ini turut dibantu oleh mahasiswa/i pilihan di UPI Kampus Purwakarta.

\section{DAFTAR PUSTAKA}

Alexander, S., Dmitri, Z., Daria, Z. (2013). Advanced Study of SDN/OpenFlow controllers. ACM CEE-SECR.

Dimas, A. M., Galura, M. S., Syamsul, Q., Rifqy, H., Eueung, M. (2017). Emulating software-defined wireless network: Bicasting scenario. 2017 3rd International Conference on Wireless and Telematics (ICWT), 76-80.

Dimas, A. M., Galura, M. S., Aris, C., R., Rifqy, H., Eueung, M. (2018). Intent-Based Path Selection for VM Migration Application with Open Network Operating System. 2018 4th International Conference on Wireless and Telematics (ICWT), pp. 1-6.

Endah, S., Syifaul, F., Galura, M. S., Hafiyyan, P.P., Dewi, I., H., P., Ichwan, N. I. (2019). Mesin Absensi RFID berbasis Internet-of-Things (IoT) untuk Meningkatkan Pengetahuan Siswa di Purwakarta terhadap Teknologi. DIKEMAS, 67-74.

Fahad, N., Qazi, H., Badlishah, A., Shamsul, J. E. (2017). Software-Defined Network Testbed Using ZodiacFX a Hardware Switch for OpenFlow. EAI Endorsed Transactions on Scalable Information Systems.

Galura, M. S., Dimas, A. M., Rifqy, H., Aris, C., R., Eueung, M. (2018). Design and Implementation of VM Migration Application on SDN-Based Network. 2018 4th International Conference on Wireless and Telematics (ICWT), 1-6.

Galura, M. S., Ichwan, N. I., Endah, S. (2020). Reactive Forwarding and Proactive Forwarding Performance Comparison on SDN-Based Network. JOIN, 115-120.

Hamid, F., HyunYong, L., Akihiro N. (2015). Software-Defined Networking: A survey. Elsevier Computer Networks.

Jacky, R., Nadine, A. (2018). SDN-based vertical handover decision scheme for $5 \mathrm{G}$ networks. IEEE Middle East and North Africa Communications Conference (MENACOMM), 1-6.

Jason, E., Scott, S. L., Matt O. (2018). Network Programability and Automation. O’Reilly Media.

Kenji, O., Performance Evaluation of an OpenFlow-based Mirroring Switch on a Laptop / Raspberry Pi. ACM digital library.

Lisnawita., Lucky, L., V., F., C., Musfawati. (2020). Pelatihan Desain Grafis Untuk Meningkatkan Kreatifitas Siswa. DINAMISIA, 231-235.

Lu, M., Xiangming, W., Luhan, W., Zhaoming, L., Raymond, K. (2018). An SDN/NFV based framework for management and deployment of service based $5 \mathrm{G}$ core network. China Communications, 86-98. 
Mininet Documentation., from https://github.com/mininet/mininet/wiki/Documentation

Muhammad, N., I., Liping, D., Iman, A., K., Talha, B., J., Muhammad, M., A. (2019). A Hybrid Solution of SDN Architecture for 5G Mobile Communication to Improve Data Rate Transmission. 28th Wireless and Optical Communications Conference (WOCC),1-5.

Shijie, Z., Weirong, J., Viktor, P. (2014). A Programmable and Scalable OpenFlow Switch using Heterogeneous SoC Platforms. ACM HotSDN.

Sindhura, B., Shobha. (2017). Implementation And Testing Of Openflow Switch Using FPGA. IEEE ICCCNT.

Thomas, D. N., Ken, G., (2013). Software Defined Network. O’Reilly.

Visi dan Misi Program Studi Sistem Telekomunikasi Kampus UPI Purwakarta. (2019)., from http://sistel.kd-purwakarta.upi.edu/?p=99 